\title{
Clearing the air: improving smoke-free policy compliance at the national oncology hospital in Armenia
}

Narine K Movsisyan ${ }^{1 *}$, Varduhi Petrosyan ${ }^{1}$, Arusyak Harutyunyan ${ }^{1}$, Diana Petrosyan ${ }^{1}$ and Frances Stillman ${ }^{2}$

\begin{abstract}
Background: Smoke-free policies shown to reduce population exposure to secondhand smoke (SHS) are the norm in hospitals in many countries around the world. Armenia, a transition economy in the South Caucasus, has one of the highest male smoking rates in the European region. Although smoking in healthcare facilities has been banned since 2005, compliance with this ban has been poor due to lack of implementation and enforcement mechanisms and social acceptability of smoking. The study aimed to develop and test a model intervention to address the lack of compliance with the de jure smoking ban. The national oncology hospital was chosen as the intervention site.
\end{abstract}

Methods: This study used employee surveys and objective measurements of respirable particles $\left(\mathrm{PM}_{2.5}\right)$ and air nicotine as markers of indoor air pollution before and after the intervention. The intervention developed in partnership with the hospital staff included an awareness campaign on SHS hazards, creation of no-smoking environment and building institutional capacity through training of nursing personnel on basics of tobacco control. The survey analysis included paired t-test and McNemar's test. The log-transformed air nicotine and PM $_{2.5}$ data were analyzed using paired t-test.

Results: The survey showed significant improvement in the perceived quality of indoor air, reduced worksite exposure to SHS and increased employees' awareness of the smoke-free policy. The number of employees reporting compliance with the hospital smoke-free policy increased from 36.0\% to 71.9\% $(\mathrm{p}<0.001)$. The overall indoor $\mathrm{PM}_{2.5}$ concentration decreased from $222 \mathrm{\mu g} / \mathrm{m}^{3} \mathrm{GM}(95 \% \mathrm{Cl}=216-229)$ to $112 \mu \mathrm{g} / \mathrm{m}^{3} \mathrm{GM}(95 \% \mathrm{Cl}=99-127)$. The overall air nicotine level reduced from $0.59 \mathrm{\mu g} / \mathrm{m}^{3} \mathrm{GM}(95 \% \mathrm{Cl}=0.38-0.91)$ to $0.48 \mu \mathrm{g} / \mathrm{m}^{3} \mathrm{GM}(95 \% \mathrm{Cl}=0.25-0.93)$.

Conclusions: The three-faceted intervention developed and implemented in partnership with the hospital administration and staff was effective in reducing worksite SHS exposure in the hospital. This model can facilitate a tangible improvement in compliance with smoke-free policies as the first step toward a smoke-free hospital and serve as a model for similar settings in transition countries such Armenia that have failed to implement the adopted smoke-free policies.

Keywords: Smoke-free policy, Smoke-free hospital, Secondhand smoke (SHS), Indoor tobacco smoke pollution, Policy compliance, Armenia, Transition economies

\section{Background}

As part of a comprehensive tobacco control strategy, smoke-free policies have been shown to reduce exposure to secondhand smoke, increase quitting rates and reduce overall smoking prevalence $[1,2]$. There is less resistance to establishing smoke-free hospitals because of their mission of prompting health. Hospitals can serve an important

\footnotetext{
* Correspondence: nmovsesi@aua.am

'School of Public Health, American University of Armenia, Yerevan, Armenia Full list of author information is available at the end of the article
}

access points to deliver smoking cessation advice [3] and healthcare professionals can be important role models to promote smoke-free norms and behaviors [4,5].

Clearing hospitals from tobacco smoke is still underway around the world. Most of the evidence on successful smoke-free policy interventions is based on the US or other high-income countries where a major shift occurred based on evidence of the harmful health effects of secondhand smoke (SHS) [1,6-8]. However, little data are available in transitional countries where resources 
are scarce to effectively implement health policies protecting the public from SHS exposure. Furthermore, more research needs to focus on what can be done when an institution has a policy but fails to adequately implement or enforce it leading to poor compliance and occurrence of smoking where it is formally prohibited.

Armenia, a transition economy in the South Caucasus, has one of the highest male smoking rates in the European region (55.1\% male; $3.7 \%$ female) and was the first in the post-soviet region to join the world treaty on tobacco control, the Framework Convention on Tobacco Control in $2004[9,10]$ The Armenian tobacco control law enacted in early 2005 prohibits smoking in educational, cultural and healthcare facilities. However, enforcement and compliance with the ban has been insufficient and a multicountry study in 2007 found high levels of tobacco indoor air pollution in public places in Yerevan, Armenia [11,12]. Thus, though being in place, the national anti-smoking policies are not properly implemented. This study aimed to develop, implement and test a model intervention to improve the compliance with the adopted (de jure) but not being actually followed smoke-free policy in the national oncology hospital in Yerevan, Armenia.

\section{Methods}

\section{Setting}

The study was conducted in a 500-bed tertiary referral hospital located in the capital city Yerevan that provides comprehensive cancer care. The hospital that had a few unsuccessful attempts to go smoke-free in recent years was chosen as an intervention site.

\section{Intervention}

The research team developed and implemented a model smoke-free intervention in fall 2009 in close cooperation with the hospital leadership. The first step of the intervention included formation of a coordinating committee in charge of the smoke-free intervention implementation in the hospital. Led by the hospital deputy director, this committee included the head nurse, a young physician experienced in tobacco control programs, the coordinator of the state tobacco control program and representatives of the research team. To inform and enrich the intervention development process the study team explored the employees' smoking-related attitudes and perceived barriers for implementation of smoke-free policy in the hospital through focus group discussions (FGDs) with nurses and physicians [13]. In addition, the research team conducted structured observations to understand in which specific indoor locations smoking occurs in the hospital. The results of the preliminary research were shared with the coordinating committee to help with development of specific intervention steps. To finalize the plan for the smoke-free intervention in the hospital, the research team also reviewed a few international case studies [14-21].

The intervention included the following three facets:

1) Information campaign about the hazards of SHS exposure and benefits of having a smoke-free hospital The information campaign targeted hospital staff, patients and visitors and used a variety of channels. The senior administration informed the hospital personnel about the smoke-free policy to be established and the intervention steps at regular staff meetings. The patients and visitors were informed about the policy through: a) large signs about the hospital smoke-free policy placed at the entrance to the hospital, b) no-smoking signs referencing the national tobacco control law and informing about penalties in case of violations posted on all floors of the hospital, c) leaflets with information on health hazards of smoking and SHS, benefits of smoke-free hospitals and the national ban of smoking in healthcare facilities, and c) verbal notifications about the smoke-free policy by hospital nurses.

2) Establishing "no-smoking" environment.

All the ashtrays were removed from the hospital and were replaced with garbage cans with a no-smoking sign.

3) Building institutional capacity to maintain no-smoking environment.

Nurse-managers of all clinical departments participated in two-day "Training of Trainers" sessions. The trainings aimed to extend nurses' knowledge on dangers of smoking and SHS exposure and their understanding of the benefits of smoke-free policy in the hospital, and to introduce the basic approaches in smoking cessation counseling. The nurse-managers received packages of relevant materials to use during the trainings of department nurses. A shorter training on basics of tobacco control was also organized for nurse aides to enhance their role in implementing smoke-free policy in the hospital. These trainings helped to build employees' support for implementation of smoke-free policy.

The official launch of the smoke-free intervention took place on the occasion of the National No Tobacco Day (October 12) and was marked by a well-covered press conference to emphasize the importance of becoming a smoke-free hospital and gain support and attention from the community at large.

\section{Study design}

To evaluate the effectiveness of the smoke-free hospital intervention, the study used an employee survey along with objective measurements of indoor tobacco smoke pollution taken before and two months after the 
intervention (panel evaluation design). The study team assessed indoor air pollution using 1) passive sampling of vapor-phase air nicotine and 2) active monitoring of concentration of respirable particles $\leq 2.5 \mu \mathrm{g} / \mathrm{m}^{3}$ (fine particular matter, $\mathrm{PM}_{2.5}$ ) in the hospital building.

\section{Survey}

The survey assessed practices, attitudes and beliefs of the hospital physicians, nurses and other staff members on smoking, worksite smoking exposure, and nonsmoking policies. All available clinical, administrative and ancillary staff members (full and part time) were eligible for the study. The trained interviewers contacted first the heads of all clinical and administrative departments and then available staff members to explain the study aims and procedures and to ask for verbal consent. The consented employees were handed a coded questionnaire to be returned in a sealed envelope. The team made several visits to cover all shifts in the departments. The study team used a self-administered questionnaire developed by the Institute for Global Tobacco Control team at Johns Hopkins University [22] that was adapted for this study. The 42-item survey questionnaire included standardized questions on socio-demographic variables and smoking status, behavior, and attitudes toward smoke-free policy, perceived indoor air quality and frequency of observed indoor smoking.

\section{Objective measurements $P M_{2.5}$ measurements}

The research team carried out $\mathrm{PM}_{2.5}$ measurements in the hospital in April and December 2009 at three purposively selected locations: the waiting area of the surgery department, the administration floor and the cafeteria, assuming their higher occupancy by visitors and staff. The $\mathrm{PM}_{2.5}$ concentrations were measured using a TSI SidePak AM510 Personal Aerosol Monitor [23]. The measurements were carried out for 30 minutes, unobtrusively (not to interfere with the natural behavior of hospital employees and visitors) using a convenient shoulder bag with a tube's end protruded outside the bag. The SidePak was pre-calibrated (calibration factor of 1.0) and the data logging interval was set to 1 minute. All data were measured by the same device.

\section{Air nicotine passive sampling}

The study team used passive samplers of vapor-phase air nicotine to measure air nicotine concentrations inside the hospital [24]. In addition to the three locations where $\mathrm{PM}_{2.5}$ measurements were taken, air nicotine samplers were placed in a few other areas of the main building. Twenty four air nicotine samplers (including two blank and two duplicate monitors for quality control) were placed before (April 2009) and after (December 2009) the intervention, each for 7 days. The study team applied the standard protocol for the air monitors' labeling, placement, collection and storage [25]. After dropping the blank and duplicate samplers and two others that were damaged or lost, 18 pairs of devices were eligible for the analysis. The air samplers were analyzed at the Exposure Assessment Facility at the Johns Hopkins Bloomberg School of Public Health (JHSPH) for nicotine content analysis by gas chromatography technique. The limit of detection was set at $0.0085 \mu \mathrm{g} / \mathrm{m}^{3}$.

\section{Ethical approval}

The Institutional Review Boards of the American University of Armenia and the JHSPH reviewed and approved the study protocols.

\section{Data analysis}

The research team entered and cleaned the survey data with SPSS11for Windows and analyzed using STATA/ SE12 statistical packages. We analyzed the survey participants' socio-demographic baseline characteristics using chi-square test for categorical and independent t-test and Anova for continuous variables. Self-reported smoking behavior, beliefs and attitudes before and after the intervention were compared using paired t-test for continuous variables and McNemar's test for categorical variables.

The study team also analyzed $\mathrm{PM}_{2.5}$ and air nicotine objective measurements data. Because of a skewed distribution of the data, we computed medians, interquartile ranges (IQRs) and geometric means (GM) to describe $\mathrm{PM}_{2.5}$ and air nicotine concentrations inside the hospital. Besides, Wilcoxon signed rank sum test was conducted to compare air nicotine medians before and after the intervention and paired t-test was performed on logtransformed air nicotine data. Additionally, we estimated percent difference in air nicotine before and after the intervention on log-transformed data.

\section{Results}

\section{Survey}

\section{Survey response rate}

In total, 295 employees out of 565 (52.0\%) filled the questionnaire at baseline and 246 at follow up (16.9\% were lost to follow up and 1 respondent did not fill the baseline questionnaire). No significant differences were found between those lost to follow up and those included in the analysis in terms of age, gender, smoking status and occupation.

\section{Survey participants' baseline characteristics}

The survey participants' mean age at baseline was 44.25 years $(\mathrm{sd}=12.04)$; the majority were women $(81.4 \%)$ and non-smokers (75.5\%). Nurses and physicians comprised $40.5 \%$ and $33.8 \%$ of the sample, correspondingly. Majority 
Table 1 Survey respondents' age and smoking behavior by gender

\begin{tabular}{lllc}
\hline & Male & Female & p-value \\
\hline $\begin{array}{l}\text { Age (yrs), mean } \pm s d \\
\text { Smoking status \% (N) }\end{array}$ & $43.37 \pm 13.58$ & $44.85 \pm 11.65$ & $0.47^{*}$ \\
$\quad$ Current smoker & $46.51(20)$ & $11.48(21)$ & $<0.001^{* *}$ \\
$\quad$ Ex-smoker & $20.93(9)$ & $4.37(8)$ & \\
$\quad$ Never smoked & $32.56(14)$ & $84.15(154)$ & \\
Smoking duration (yrs), mean \pm sd & $17.82 \pm 11.48$ & $16.28 \pm 10.77$ & $0.62^{*}$ \\
Cigarettes/day, mean \pm sd & $20.33 \pm 15.50$ & $9.93 \pm 8.73$ & $0.032^{*}$ \\
Cigarettes/day at work, mean \pm sd & $9.58 \pm 8.03$ & $2.94 \pm 5.26$ & $0.008^{*}$ \\
Quit attempts in 30 days, \% (N) & $27.78(5)$ & $40.00(6)$ & $0.46^{* *}$ \\
\hline
\end{tabular}

*independent t-test.

**chi-square test.

(70.9\%) of the study participants at baseline reported never smoking, $17.3 \%$ were current smokers and $7.2 \%$ exsmokers. Smoking prevalence differed significantly across the occupation and gender, but not age.

Nearly half (46.5\%) of male employees were current smokers as opposed to $11.5 \%$ of women $(\mathrm{p}<0.001)$. Male employees smoked more cigarettes as compared to female during working hours (9.6 vs. 2.9, $\mathrm{p}<0.01$ ), as well as per day $(20.3$ vs. $9.9, \mathrm{p}<0.05)$ (Table 1$)$.

Smoking rates were the highest among physicians compared to nurses and ancillary staff (34.2\% vs. $8.8 \%$ and $10.7 \%$, correspondingly) (Table 2). The duration of smoking (years) and the number of monthly quit attempts within the last month did not differ across occupation and gender (Tables 1 and 2).

\section{Indoor SHS exposure}

Hospital employees reported significant improvement in perceived indoor air quality related to tobacco smoke at follow up. The proportion of respondents who assessed it as good or fair increased from $69.5 \%$ to $83.6 \%$ ( $<<0.001)$.
There was also a significant reduction in observing smoking inside the hospital building, including cafeteria, patient lounges, corridors, and stairwells, but not in physicians' offices (Table 3).

\section{Smoke-free policy awareness}

Employees' awareness of the smoke-free policy improved significantly from $37.7 \%$ at baseline to $63.4 \%$ at follow up $(\mathrm{p}<0.001)$ (Table 3). Moreover, the number of respondents who reported that the hospital smoke-free policy was observed increased from $36.0 \%$ to $71.9 \%$ ( $<<0.001$ ).

\section{Smoking behavior}

Survey respondents reported less cigarette smoking and more quitting attempts at follow up than at baseline. Thus, the number of cigarettes smoked daily and during work hours decreased from $15.8(10.8-20.8)$ and 6.5 (3.9- 9.2) to 14.1 (9.6-18.7) and 5.7 (3.3- 8.0), correspondingly. At the same time, $40.0 \%$ of smokers recalled a quitting attempt within the last month at follow up as compared to $33.3 \%$ at baseline. However, these changes in respondents' smoking behavior were not statistically significant.

\section{Objective measurements}

$\mathrm{PM}_{2.5}$ data analysis

The overall indoor $\mathrm{PM}_{2.5}$ concentration decreased from $222 \mu \mathrm{g} / \mathrm{m}^{3}$ GM $\left(95 \% \mathrm{CI}=216-229 \mu \mathrm{g} / \mathrm{m}^{3}\right)$ to $112 \mu \mathrm{g} / \mathrm{m}^{3}$ GM $\left(95 \% \mathrm{CI}=99-127 \mu \mathrm{g} / \mathrm{m}^{3}\right)$. The paired t-test using log-transformed data showed that changes of $\mathrm{PM}_{2.5}$ concentration over time in all three locations were statistically significant, including the decrease in waiting $(\mathrm{p}=0.03)$ and administrative areas $(\mathrm{p}<0.001)$ and the increase in cafeteria $(\mathrm{p}<0.001)$. Figure 1 graphically presents the real-time $\mathrm{PM}_{2.5}$ flows in three locations at baseline and follow up.

\section{Air nicotine analysis}

Aggregated air nicotine level decreased by $18.8 \%$ at follow up, from $0.59 \mu \mathrm{g} / \mathrm{m}^{3} \mathrm{GM}(95 \% \mathrm{CI}=0.38-0.91)$ to

Table 2 Survey respondents' age and smoking behavior by occupation

\begin{tabular}{lllll}
\hline & Nurses & Physicians & Non-clinical staff & p-value \\
\hline Age (yrs), mean $\pm s d$ & $41.51 \pm 10.89$ & $43.08 \pm 12.43$ & $51.39 \pm 10.56$ & \\
Smoking status\% $(\mathrm{N})$ & & & & $<.001^{*}$ \\
Current smoker & $8.89(8)$ & $34.18(27)$ & $10.53(6)$ \\
Ex-smoker & $1.11(1)$ & $16.46(13)$ & $5.26(3)$ \\
Never smoked & $90.0(81)$ & $49.37(39)$ & $84.21(48)$ \\
Smoking duration (yrs), mean \pm sd & $15.67 \pm 8.73$ & $17.39 \pm 10.37$ & $17.29 \pm 17.5$ & $0.92^{* *}$ \\
Cigarettes/day, mean \pm sd & $6.67 \pm 7.26$ & $17.50 \pm 15.24$ & $20.00 \pm 7.07$ & $0.19^{*}$ \\
Cigarettes/day at work, mean \pm sd (N) & $1.00 \pm 2.65$ & $7.75 \pm 7.99$ & $9.0 \pm 7.62$ & $<0.09^{*}$ \\
Quit attempts in 30 days, \% (N) & $16.67(1)$ & $34.78(8)$ & $50.00(2)$ & $0.53^{* *}$ \\
\hline
\end{tabular}


Table 3 Indoor air quality, awareness of the worksite smoke-free policy and indoor smoking behavior before and after the intervention

\begin{tabular}{llll}
\hline Question & Before & After & p-value* \\
& $\%(N)$ & $\%(N)$ & \\
\hline
\end{tabular}

The air quality (tobacco smoke level) in your building is:

$\begin{array}{llll}\text { Good/Fair } & 69.5(162) & 83.6(188) & <0.001 \\ \text { Poor } & 30.5(71) & 16.4(37)\end{array}$

$30.5(71)-16.4(37)$

How often do you smell tobacco while you are at work?

$\begin{array}{lll}\text { Frequently } & 53.2(124) & 41.8(95) \\ \text { Infrequently/Never } & 46.8(113) & 58.2(142)\end{array}$

Does the hospital have any policy against smoking in the buildings?

$$
\begin{array}{llll} 
& \text { "Yes" answers } & 75.2(174) & 96.4(213)
\end{array}
$$

Are the official policies about smoking in the building followed?

"Yes, it is followed" answers 36.0(82) $\quad 71.9(161) \quad<0.001$

In the past 30 days, have you seen people smoking in the following areas?

"Yes" answers

\begin{tabular}{lllr} 
Cafeteria & $39.6(88)$ & $25.8(54)$ & $<0.001$ \\
Offices & $57.7(131)$ & $39.6(86)$ & 0.42 \\
Corridors & $77.5(179)$ & $53.9(119)$ & $<0.001$ \\
Stairwells & $80.2(186)$ & $49.6(109)$ & $<0.001$ \\
Lounges in patient care areas & $33.5(76)$ & $19.3(41)$ & $<0.001$ \\
Restrooms & $23.3(52)$ & $14.9(31)$ & $<0.001$ \\
Outside the building & $97.4(226)$ & $95.9(212)$ & $<0.001$ \\
\hline
\end{tabular}

${ }^{*}$ McNemar test.

$0.48 \mu \mathrm{g} / \mathrm{m}^{3} \mathrm{GM}(95 \% \mathrm{CI}=0.25-0.93)$ (see Additional file 1). A reduction in geometric mean values of air nicotine was observed in every location except the doctors' offices and stairwells; however, these differences were not statistically significant. We found the greatest reduction in the air nicotine GMs in administrative offices, cafeteria and patient lounges, followed by waiting areas (50.98\%; $34.76 \% ; 31.58 \%$ and $19.50 \%$, accordingly). On the contrary, the levels of air nicotine increased in doctors' offices and stairwells.

\section{Discussion}

While a number of studies examined implementation of smoke-free hospital policies in different parts of the world $[15,19,21,26,27]$, none of them were carried out in a transition economy such as Armenia and only a few used objective measurements of indoor air quality. The Armenian legislation prohibits smoking in healthcare institutions; however, this policy has not been sufficiently adhered since its enactment in 2005 [12]. Failure to implement and enforce SHS policies undermines the intent to create a safe and healthy environment. It also builds skepticism towards the occurrence of a meaningful change, as social cognitive theory suggests, due to interaction between person's past experience, environment, and behavior [28]. Such situations, where a policy formally adopted on the national level is not actually adhered to in particular setting(s), are not a rare case in emerging and re-emerging economies, for example, in China [29]. The goal of our study was to develop and test a model intervention to improve the compliance with de jure smoking ban in hospitals in Armenia. Our study proved the intervention to be successful in significantly reducing indoor smoking at the hospital though we did not reach $100 \%$ smoke-free. However, the intervention was a good start for improving the compliance with the smoke-free policy as required by the national legislation and it could be scaled up to other hospitals in Armenia. This model can be applied also in neighboring countries with a similar issue of poor compliance with smoke-free policies.

We have identified several barriers to successful implementation of smoke-free policy in hospitals, including high prevalence of smoking among the hospital physicians and their reluctance to accept their role as opinion leaders related to smoking ban [13]. Therefore, the implementation of a smoke-free intervention in the study

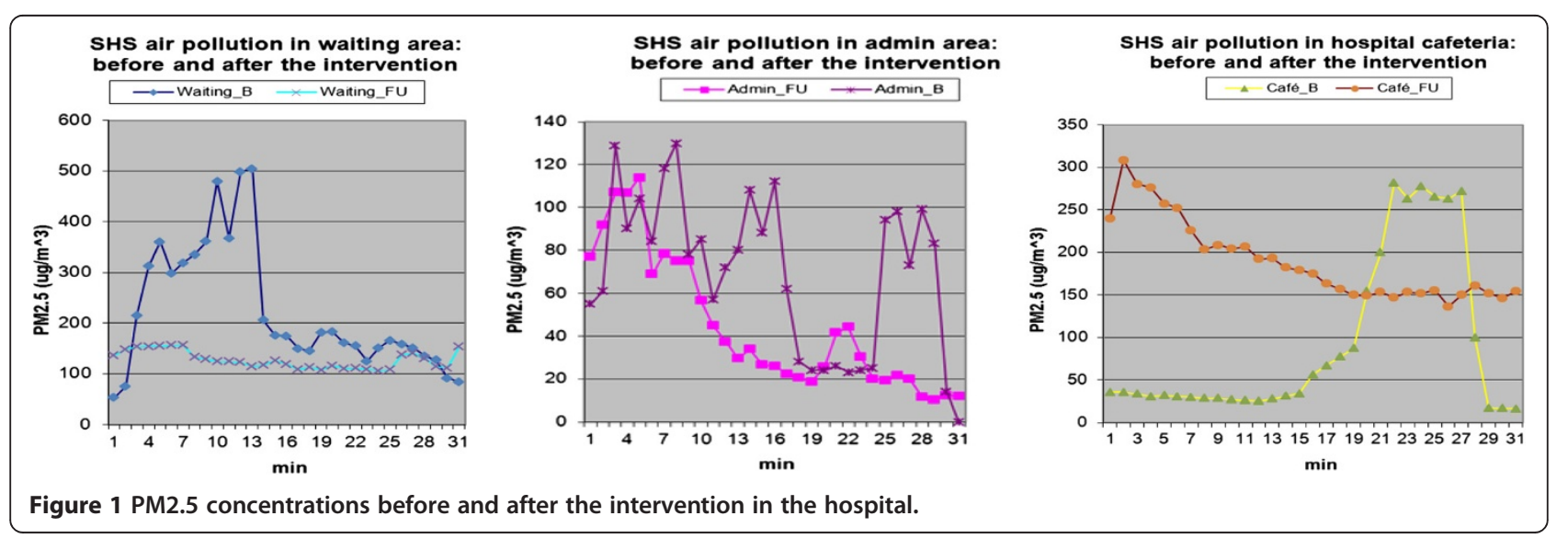


setting did require a careful planning to address these barriers and not to stigmatize smoking employees. The essential part of this intervention was identifying the lead person who had the authority and willingness to support and lead the effort on part of the hospital administration. The intervention did not require much financial resources; but the leadership and commitment of the hospital's top administration was crucial.

Our findings suggested significant improvements in employees' awareness of the smoke-free policy and the indoor air quality after the intervention. These findings from the employee survey were confirmed, to a certain extent, by the objective measurements of air nicotine and $\mathrm{PM}_{2.5}$ pollution. We observed reduction of air nicotine in all indoor locations except doctors' offices and stairwells. The $\mathrm{PM}_{2.5}$ levels decreased in the waiting and administrative areas but increased in the cafeteria. The air nicotine in this particular study was more informative as a proxy marker of indoor air pollution because the data were cumulative for seven days while $\mathrm{PM}_{2.5}$ measurements were carried for 30 minutes. Therefore, both the survey and objective data suggest that smoking went down in most public areas and increased in physicians' offices, i.e. that smoking shifted from public areas to less visible places. This could be a good accomplishment for the initial stage of establishing smoke-free policies. Future interventions would need to target smoking in physician's offices and other less visible areas, such as stairwells. Installation of smoke detectors could complement the educational approach in addressing the "hidden" smoking.

The intervention did not reduce the smoking rates among the hospital employees. However, the smokers reported smoking fewer cigarettes at work and per day and more smokers recalled a quitting attempt in the past 30 days at follow up than at baseline.

The short-term evaluation of the intervention showed positive effects. However, without a proper follow up and leadership these effects may diminish over time $[26,30]$. The international experience suggests that when smoke-free policy becomes a requirement in hospital accreditation process as in the US or an adopted code of practice as in the European Smoke Free Hospitals Network, this may substantially help to sustain efforts toward clearing up the smoke in hospitals [26,31]. In this study, the intervention focused mainly on the hospital staff and did not target patients and their caretakers. Future interventions could include smoking cessation programs for employees and smoking cessation counseling to patients during hospitalization.

This study was implemented at one facility limiting the generalizability of the findings. In addition, the study findings might be affected by seasonal variations in indoor smoking because the objective measurements were conducted in April (baseline) and December (follow up).

\section{Conclusions}

Based on the study findings, we suggest that the threefaceted intervention developed and implemented in a partnership with the hospital administration and staff was effective in reducing worksite SHS exposure in the hospital. This model can facilitate a tangible improvement in compliance with the smoke-free hospital policy as a first step toward a smoke-free hospital and serve as a model for similar settings in transition countries such Armenia that have failed to implement the adopted smoke-free policies.

\section{Additional file}

Additional file 1: Air nicotine concentrations before and after the intervention in the hospital.

\section{Competing interests}

The authors declare that they have no competing interests.

\section{Authors' contributions}

NM, VP and FS conceptualized the scope of this paper. NM performed the statistical analysis and drafted the manuscript. All authors contributed to the design of the intervention and its evaluation. DP and $\mathrm{AH}$ supervised data collection and the intervention implementation. All authors contributed to the final manuscript, reviewed and approved it.

\section{Acknowledgements}

The authors thank the hospital staff and administration for participation and cooperation.

This study is a part of a larger project that was funded by the Johns Hopkins FAMRI (Flight Attendant Medical Research Institute) Center of Excellence.

\section{Author details}

${ }^{1}$ School of Public Health, American University of Armenia, Yerevan, Armenia ${ }^{2}$ Institute for Global Tobacco Control, Bloomberg School of Public Health, Johns Hopkins University, Baltimore, MD, USA.

Received: 4 August 2014 Accepted: 8 December 2014

Published: 13 December 2014

\section{References}

1. Fichtenberg CM, Glantz SA: Effect of smoke-free workplaces on smoking behaviour: systematic review. BMJ 2002, 325(7357):188.

2. Longo DR, Johnson JC, Kruse RL, Brownson RC, Hewett JE: A prospective investigation of the impact of smoking bans on tobacco cessation and relapse. Tob Control 2001, 10(3):267-272.

3. Rigotti NA, Arnsten JH, McKool KM, Wood-Reid KM, Pasternak RC, Singer DE: Smoking by patients in a smoke-free hospital: prevalence, predictors, and implications. Prev Med 2000, 31(2 Pt 1):159-166.

4. Sarna L, Bialous SA, Sinha K, Yang Q, Wewers ME: Are health care providers still smoking? Data from the 2003 and 2006/2007 tobacco use supplement-current population surveys. Nicotine Tob Res 2010, 12(11):1167-1171.

5. Nett LM: The physician's role in smoking cessation. A present and future agenda. Chest 1990, 97(2 Suppl):28S-32S.

6. USDHHS: The health consequences of involuntary smoking. A report of the surgeon general. Rockville, Maryland: US Department of Health and Human Services; 1986

7. $\mathrm{NCl}$ : Health effects of exposure to environmental tobacco smoke: the report of the California Environmental Protectional Agency. In Smoking and Health Monograph 10. Bethesda, MD: National Cancer Institute; 1999.

8. Longo DR, Brownson RC, Kruse RL: Smoking bans in US hospitals. Results of a national survey. JAMA 1995, 274(6):488-491.

9. Mackay J, Eriksen MP, Ross H: The tobacco atlas. 4th edition. Atlanta, Ga: American Cancer Society; 2012. 
10. WHO: Framework Convention on Tobacco Controls. Geneva: World Health Organization; 2003

11. Hyland A, Travers MJ, Dresler C, Higbee C, Cummings KM: A 32-country comparison of tobacco smoke derived particle levels in indoor public places. Tob Control 2008, 17(3):159-165.

12. Movsisyan NK, Petrosyan V: Analytical review of the tobacco control policy in Armenia 2005-2007. Yerevan, Armenia: American University of Armenia; 2008

13. Movsisyan NK, Petrosyan V, Harutyunyan A, Petrosyan D, Muradyan A, Stillman F: Smoking behavior, attitudes, and cessation counseling among healthcare professionals in Armenia. BMC Public Health 2012, 12:1028.

14. Etter JF, Ronchi A, Perneger T: Short-term impact of a university based smoke free campaign. J Epidemiol Community Health 1999, 53(11):710-715.

15. Hurt RD, Berge KG, Offord KP, Leonard DA, Gerlach DK, Renquist $C L$, O'Hara MR: The making of a smoke-free medical center. JAMA 1989, 261(1):95-97.

16. McKee M, Gilmore A, Novotny TE: Smoke free hospitals. BMJ 2003, 326(7396):941-942

17. Stillman FA, Becker DM, Swank RT, Hantula D, Moses H, Glantz S, Waranch HR: Ending smoking at the Johns-Hopkins-medical-institutions - an evaluation of smoking prevalence and indoor air-pollution. Jama J Am Med Assoc 1990, 264(12):1565-1569.

18. Andrews JJL: Reducing smoking in the hospital. An effective model program. CHEST J 1983, 84(2):206-209.

19. Fernández E, Fu M, Martínez C, Martínez-Sánchez JM, López MJ, Martín-Pujol A, Centrich F, Muñoz G, Nebot M, Saltó E: Secondhand smoke in hospitals of Catalonia (Spain) before and after a comprehensive ban on smoking at the national level. Prev Med 2008, 47(6):624-628.

20. VINACOSH: Establishment of smoke-free hospitals: a practical guide with a CD and toolkit. Vietnam Committee on Smoking and Health; 2008. [http://www.fhi360.org/sites/default/files/media/documents/ Establishment\%20of\%20smoke-free\%20hospitals\%20-\%20A\%20practical\% 20guide\%20and\%20toolkit.pdf] Data accessed:March 2014

21. Donchin M, Baras M: A "smoke-free" hospital in Israel—a possible mission. Prev Med 2004, 39(3):589-595.

22. Stillman FA, Hantula DA, Swank R: Creating a smoke-free hospital: attitudes and smoking behaviors of nurses and physicians. Am $J$ Health Promot 1994, 9(2):108-114.

23. Model AM510 SIDEPAKTM Personal Aerosol Monitor: User Guide. Shoreview, MN, USA: TSI Inc; 2003. [http://tobaccofreeair.org/downloads/1980456b\% 20SidePak\%20manual.pdf]. Data accessed: November 2013.

24. Hammond SK, Leaderer BP: A diffusion monitor to measure exposure to passive smoking. Environ Sci Technol 1987, 21(5):494-497.

25. Navas-Acien A, Peruga A, Breysse P, Zavaleta A, Blanco-Marquizo A, Pitarque R, Acuña M, Jiménez-Reyes K, Colombo VL, Gamarra G, Stillman FA, Samet J: Secondhand tobacco smoke in public places in Latin America, 2002-2003. JAMA 2004, 291(22):2741-2745

26. Fernández E, Martínez C, Fu M, Martínez-Sánchez JM, López MJ, Invernizzi G, Ouranou A, Dautzenberg B, Nebot M: Second-hand smoke exposure in a sample of European hospitals. Eur Respir J 2009, 34(1):111-116.

27. Rigotti NA: II. Smoking cessation in the hospital setting-a new opportunity for managed care. Tob Control 2000, 9(suppl 1):i54.

28. Bandura A: Organizational applications of social cognitive theory. Aust $J$ Manag 1988, 13(2):275-302.

29. Abdullah AS, Qiming F, Pun V, Stillman FA, Samet JM: A review of tobacco smoking and smoking cessation practices among physicians in China: 1987-2010. Tob Control 2011, 22(1):9-14.

30. López MJ, Nebot M, Schiaffino A, Pérez-Ríos M, Fu M, Ariza C, Muñoz G, Fernández E: Two-year impact of the Spanish smoking law on exposure to secondhand smoke: evidence of the failure of the 'Spanish model'. Tob Control 2011, 21(4):407-411.

31. Williams SC, Hafner JM, Morton DJ, Holm AL, Milberger SM, Koss RG, Loeb JM: The adoption of smoke-free hospital campuses in the United States. Tob Control 2009, 18(6):451-458

doi:10.1186/1471-2407-14-943

Cite this article as: Movsisyan et al:: Clearing the air: improving smokefree policy compliance at the national oncology hospital in Armenia. BMC Cancer 2014 14:943.

\section{Submit your next manuscript to BioMed Central and take full advantage of:}

- Convenient online submission

- Thorough peer review

- No space constraints or color figure charges

- Immediate publication on acceptance

- Inclusion in PubMed, CAS, Scopus and Google Scholar

- Research which is freely available for redistribution 